\title{
Resilience and Mental Health Risks among Syrian Refugees in Europe: A Cultural Perspective
}

Received: September 20, 2017; Accepted: September 28, 2017; Published: October 08, 2017

\section{Introduction}

Dated from 2011, the civil war in Syria has forced more than half of the Syrians to leave their home. This crisis is defined as the world's largest humanitarian tragedy since the World War II. Ransom and kidnap, rape, sexual slavery, brutal executions, disappearances, forced displacement have become regular part of the daily news from the region. As for today, the total number of people in need of humanitarian assistance in Syria has reached 12.2 million, approximately 7.6 million of whom are internally displaced; the largest number of internally displaced persons in any country in the world [1]. Refugees from Syria are now the largest refugee population in the world with more than four million Syrian refugees in neighbouring countries and the larger region, such as Europe. The continuation of multi-sided armed conflict has lead to new cross-border movements of refugees each year, increasing the number of Syrians seeking protection in Europe [2-4].

In response to the humanitarian needs, many EU countries have received applications from asylum seekers and refugees. The report of UNHCR in 2014 claims 562.680 asylum applications records in 38 European countries, which reflects an increase of $24 \%$ in comparison to the same period of $2013[5,6]$. The number of people applying for asylum in the European Union was more than doubled in 2015, reaching a record 1.26 million, according to the EU statistics agency. Syrians accounted for almost a third, with 362,775 people seeking shelter in Europe, followed by Afghans and Iraqis. Since 2016, rapid growth rate of the refugee population has been decelerating slightly $[7,8]$.

Eurostat [9] reports that the highest number of positive asylum decisions was recorded in Germany, followed by Sweden, France and Italy, the United Kingdom and the Netherlands under the UN's humanitarian resettlement program. Those aforementioned states accounted for $81 \%$ of the total number of acceptances issued in the EU-28 $[9,10]$.

In conjunction with their educational needs and possibility to work and settlement in the countries of migration, the health situation of the refugees is a large field of concern. A United Nations and Government of Syria joint assessment mission has specified mental health and psychosocial support as one of the

\author{
Nazlı Balkır Neftçi $i^{1 *}$ and \\ Önver Andreas Çetrez ${ }^{2}$ \\ 1 Department of Psychology, Işık \\ University, Istanbul, Turkey \\ 2 Department of Psychology, Uppsala \\ University, Uppsala, Sweden
}

\begin{abstract}
*Corresponding author: Nazlı Balkır Neftçi, PhD

झ nazli.balkir@isikun.edu.tr

Department of Psychology, Işık University, Istanbul, Turkey.
\end{abstract}

Tel: (0212)2864911/6092

Citation: Neftçi NB, Çetrez ÖA (2017)

Resilience and Mental Health Risks among Syrian Refugees in Europe: A Cultural Perspective. Acta Psychopathol. Vol. 3 No. 5:65

most major concerns resulting from the current crisis [11]. In light of this unique set of challenges, there is an ongoing need for information on the mental health issues and culturally appropriate interventions not only for reducing symptoms of psychological distress but also for enhancing qualities of psychological and social wellbeing of this marginalized population. Hence, the specific objectives of the current paper are to: 1) provide basic information on the common mental health problems caused by the crisis; 2) discuss cultural issues in the conceptualizations of mental health problems, resilience enhancing practices and possible expectations about the appropriate healing strategies in order to promote mental health status and psychiatric care of Syrian refugees in Europe.

\section{Major Challenges: Mental Health Risks and Service Utilization among Syrian Refugees in Europe}

As clearly detailed above, refugee populations have a history of gross human rights violations from their home country. Additionally, other issues on the front burner of many refugees were traumatic grief for their family members who were either left behind or already outridden to some other countries as well as severe anxiety due to the ambiguity of their future 
and the doubts about the possibility of reunion of their family. Concordantly, literature clearly suggests that exposure to a constant distressing and traumatic events, loss of resources, forced displacement and lack of security can undermine mental health and increase risk for maladaptation [12]. To crown it all, the adaptation to their new environment brings along additional difficulties that refugees have to cope with when they integrate new styles and norms of interpersonal relationships, social habits and rules, organization of community services, etc. to initiate a new life in a different culture [13]. Despite the increased risk for mental disorders among crisis affected Syrian refugees, epidemiologic studies are limited and fragmented. Nevertheless, there is some evidence yielding that the refugees from Syria manifest a wide range of symptoms related to past traumatic experiences. These symptoms include emotional (i.e. sadness, grief, fear, frustration, anxiety, anger and despair); cognitive (i.e. loss of control, helplessness, rumination, boredom and hopelessness); physical (fatigue, problems of sleep and appetite, somatic symptoms) components [14]. Although these symptoms are found to be prevalent, some studies remarked high levels of resilience among this particular refugee group and suggested that such manifestations do not necessarily indicate psychopathology (e.g. posttraumatic stress disorder, depression), unless they cause intense distress and functional impairment [15]. Congruently, a growing number of research emphasize the importance of the establishment of the interventions that promote such resiliency in coping with distress among Syrian refugees [16].

Despite the fact that immigrants and refugees are a high risk category for mental health problems, recent studies provide evidence that they are less likely to seek professional care, exhibit higher rates of drop out and lower rates of compliance to treatment compared to their native counterparts [17]. Such treatment gap might be partially due to the fact that individuals from Middle-Eastern cultural backgrounds often have different conceptualizations of mental illness and appropriate healing strategies, as defined by their own social and cultural context, which can be different from those found in European societies [18-20]. Such cultural differences often result in discordance between expectations of patients and of clinicians from the treatment. This generally undermines communication and therefore leads to unexplained high dropout rates [21]. In order to prevent poorer health results, the exploration of such sociocultural differences between patient and clinician must occur. Hence, the role of culture in the conceptualizations of mental health problems, resilience enhancing practices and possible expectations about the appropriate healing strategies should be recognized as an important step in improving mental health care for culturally diverse Syrian refugee population.

\section{Cultural Aspects of Mental Distress, Resilience and Recovery}

Western models of illness usually adopt etic approach that evaluates refugees' manifestations of mental distress in terms of psychopathology as conceptualized by biomedically based psychiatry and offer treatment options to enhance their well- being accordingly $[22,23]$. This approach is, however, criticized by many professionals, advocating that Western models of illness cannot be applied across cultures and acknowledging the profound effect of culture on meanings that people impart to their illness [24-26].

Explanatory model (EM) perspective, coined by medical anthropologist Arthur Kleinman [27], has directed attention to eliciting the cognitive aspects of individuals' understanding of their illness, i.e. mental distress in this context, in order to unravel their own healing strategies. In essence, EM is the one's beliefs of the cause, severity, and prognosis of an illness (i.e. What happened? Why it had happened? How serious is it?) and the expected healing strategies (i.e. Who/what can heal it?) [27]. It has been stated that explanatory models of illness are, to a large extent, coherent with general cultural beliefs about illness and healing. Causal beliefs (i.e. Why it had happened?) are suggested to be a pivotal cognitive process in the construction of EM and play an important role in the organization of effective healing strategies as well as resilience factors $[28,29]$. Correspondingly, several anthropological studies differentiated between Western and non-Western causal beliefs about mental distress [21]. It has been stated that social and supernatural etiologies are associated with more traditional societies of non-Western cultures whereas natural or patient-centered explanations of distress are more commonly found in Western societies [30]. Likewise, Littlewood and Lipsedge [31] underlined the historical importance of religion in such traditional cultures and its significance in the meaning making of mental distress. For instance, among Europeans, the causes of psychological distress is more likely to located within the individual (e.g. stress, organic causes) whereas many societies from the Middle East cite supra-individual or social relationships (e.g. interpersonal or familial conflicts, fate, will of god) as cause of their current distress [21].

Expectedly, individuals who adopt religion and spirituality in the meaning making of mental distress, are more likely to seek help for their problems through religious coping [32]. Whereas, individuals who conceptualizes mental distress as emotional reactions to situations resulting mainly from familial or social problems, are more likely to seek social support as a cure for their current situation [33]. For instance, in a study conducted with immigrants with the origin of India and Bangladesh, Hatfield et al., [34], reported that family and social stress and a religious dimension (will of god) was prominent, in terms both of causes and healing of mental ill-health. There was no evidence of rejection of mainstream services however, the value of prayer mentioned repeatedly as a way of coping with mental distress. Likewise, in a research conducted with Assyrian refugees in Istanbul, religious coping was found to be negatively related to somatic symptoms through escalating resilience and self-efficacy [35]. Indeed, Sleijpen et al. [36] in a review of 26 studies, identified the following six sources of resilience in young refugees, who had resettled in Western countries: social support, religion, hope, acculturation strategies, education and avoidance.

Despite modernizing and acculturative influences, studies demonstrated that culture is a major determinant of how 
individuals evaluate and react to distress. All of which determine the choice of coping strategies and adherence to conventional treatment plans. Unlike in European societies, existing research clearly document the importance of religion, prayer and familial or social relationships as the key aspects of beliefs about the nature of mental illness and coping styles among individuals from Middle Eastern societies. Once refugees are in contact with a clinician, they stand on the other side of a therapeutic relationship that is yet to be established. It is solely up to clinicians to bridge such cultural gap. Thus, recognizing the client's explanatory of mental distress and healing beliefs and exploring the ways to incorporate these into the treatment plan would be the key attempts to create maximum effectiveness.

\section{Conclusions}

Addressing the mental health issues and cultural features of resilience and recovery among Syrian refugee population is a key challenge and a great necessity for mental health care service providers in demographically changing context. Given that the mental distress is framed in terms of disruption in social relationships or in the spiritual realm in most of the Middle Eastern refugees, these individuals usually prefer to seek support of friends or family or implement religious practices such as praying, in order to promote their adaptation in the face of adversity. Culture influences not only one's understanding

\section{References}

$1 \mathrm{http} / / / \mathrm{www} .3$ rpsyriacrisis.org/crisis

2 http://www.unhcr.org/ syriarrp6/docs/Syria-rrp6-full-report.pdf

3 http://www.unocha.org/syria

4 https://reliefweb.int/report/lebanon/syrian-refugees-inter-agencyregional-update-19-march-2015

5 http://www.unhcr.org/5329b15a9.pdf

6 http://www.unhcr.org/551128679.pdf

7 http://www.unhcr.org/576408cd7.pdf

8 http://www.unhcr.org/5943e8a34.pdf

9 http://ec.europa.eu/eurostat/web/conferences

10 https://www.amnesty.org/en/latest/research/2015/02/annualreport-201415/

11 Quosh C (2013) Mental health, forced displacement and recovery: integrated mental health and psychosocial support for urban refugees in Syria. Intervention 11: 295-320.

12 Silove D (1999) The psychosocial effects of torture, mass human rights violations and refugee trauma: towards an integrated conceptual framework. J Nerv Ment Dis 187: 200-207.

13 Rios PD (2008) Migration and psychopathology. Ann Clin Health Psychol 4: 15-25.

14 Vukcevic M, Dobric J, Puric D (2014) Psychological characteristics of Asylum seekers from Syria, in survey of the mental health of Asylum seekers in Serbia. UNHCR Serbia: Belgrade.

15 Hassan G, Ventevogel P, Jefee-Bahloul H, Barkil-Oteo A, Kirmayer LJ of mental distress and strategies to adapt such distressing experiences, but also shapes attitudes towards and compliance to treatment. Literature has pointed to the need for culturally competent providers who are able to recognize and share the patient's illness model and present interventions that fit the patient expectations [27,37-39]. Therefore, two main messages can be derived from the current paper. First, given that the most refugees are found to be highly resilient [15], working on the establishment of culturally relevant conditions that foster their resilience would serve as a preventive intervention that is targeted at mental disorders. Second, while working with refugee patients, it has been shown to be crucial to remain open to multiple explanatory models including biomedical, psychological, religious and traditional ones to enhance communication with the refugee patients [40]. This may refer to the fact that while clinicians provide psychological treatment, the patients may maintain their beliefs regarding what they believe/practice is also effective for their treatment. In other words, it may be helpful for keeping these patients in treatment by remaining open not only to alternative explanatory models but also to the use of traditional forms of treatment $[32,41]$. Thus, refugee patients who have difficulties in maintaining contact with clinicians may be more likely to remain in treatment if they attain culturally congruent care process.

(2016) Mental health and psychosocial wellbeing of Syrians affected by armed conflict. Epidemiol Psychiatr Sci 25: 129-141.

16 Pacione L, Measham T, Rousseau C (2013) Refugee children: mental health and effective interventions. Curr Psychiatry Rep 15: 1-9.

17 Bhugra D (2003) Migration and depression. Acta Psychiatr Scand Suppl 418: 67-73.

18 Draguns JG (1989) Normal and abnormal behavior in cross-cultural perspective: specifying the nature of their relationship. In: Berman JJ Edn, Cross-cultural perspectives. Lincoln, NE US: University of Nebraska Press. Nebr Symp Motiv 37: 235-277.

19 Mente D (1995) Whose truth? Whose goodness? Whose beauty? Am Psychol 50: 391.

20 Sato T (2001) Autonomy and relatedness in psychopathology and treatment: a cross cultural formulation. Genet Soc Gen Psychol Monogr 127: 89-127.

21 Marsella AJ, White GM (1982) Cultural conceptions of mental health and therapy. Boston: Reidel.

22 Hodes M (2000) Psychologically distressed refugee children in the United Kingdom. Child Psychol Psychiatry Rev 5: 57-68.

23 Kinzie JD, Sack WH, Angell RH, Manson SM, Ben R (1986) The psychiatric effects of massive trauma on Cambodian children: I. The children. J Am Acad Child Psychiatry 25: 370-376.

24 Littlewood R (1990) From categories to contexts: a decade of new cross-cultural psychiatry. Br J Psychiatry 156: 308-327.

25 Bhugra D, Mastrogianni A (2004) Globalisation and mental disorders: overview with relation to depression. Br J Psychiatry 184: 10-20.

26 Patel V (2001) Cultural factors and international epidemiology. $\mathrm{Br}$ Med Bull 57: 33-45. 
27 Kleinman A (1978) Concepts and a model for the comparison of medical systems as cultural formulation. Genet Soc Gen Psychol Monogr 127: 89-127.

28 Hall LE, Tucker CM (1985) Relationships between ethnicity, conceptions of mental distress and attitudes associated with seeking psychological help. Psychol Rep 57: 907-916.

29 Kirmayer LJ, Young A, Robbins JM (1994) Symptom attribution in cultural perspective. Can J Psychiatry 39: 584-595.

30 Landrine H, Klonoff EA (1992) Culture and health-related schema. Health Psychol 11: 267-276.

31 Littlewood R, Lipsedge M (1997) Aliens and alienists. Ethnic minorities and psychiatry, $3^{\text {rd }}$ Edn, Routledge: London.

32 Razali SM, Hasanah Cl, Aminah K, Subramaniam M (1998) Religioussociocultural psychotherapy in patients with anxiety and depression. Aust N Z J Psychiatry 32: 867-872.

33 Balkır N (2013) Mental illness models and help seeking behaviors among turkish immigrant patients in Europe. In Barnow $S$ \& Balkir $\mathrm{N}(\mathrm{Edn})$. Cultural variations in psychopathology: from research to practice. Göttingen: Hogrefe Publications.

34 Hatfield B, Mohamad H, Rahim Z, Tanweer H (1996) Mental health and the Asian communities: a local survey. $\mathrm{Br} J$ of Social Work 26: 315-336.
35 Balkır N, Cetrez AÖ (2015) Happily ever after? Mental health status, illness models and psychological coping among two immigrant/ refugee groups. Congress of the International Association for the psychology of Religion 17.08-20.08.2015.

36 Sleijpen M, Boeije HR, Kleber RJ, Mooren T (2015) Between power and powerlessness: a meta-ethnography of sources of resilience in young refugees. Ethn Health 21: 158-180.

37 Good BJ, Delvecchio-Good MJ (1980) The meaning of symptoms: a cultural hermeneutics model for clinical practice. In Eisenberg $L$ \& Kleinman A (Edn), The Relevance of Social Science for Medicine. Boston: D. Reidel Publishing, pp: 165-196.

38 Lin T, Lin M (1978) Service delivery issues in Asian-North American communities. Am J Psychiatry 135: 454-456.

39 White GM, Marsella AJ (1987) Introduction: cultural conceptions in mental health research and practice. In Marsella AJ, White GM (Edn), Cultural conceptions of mental health and therapy. Dordrecht, The Netherlands: Reidel, pp: 3-38.

40 Kirmayer LJ, Robbins JM (1996) Patients who somatisize in primary care: a longitudinal study of cognitive and social characteristics. Psychol Med 26: 937-951.

41 De Jong JTVM (1994) Ambulatory mental health care for migrants in the Netherlands. Curare 17: 5-34. 